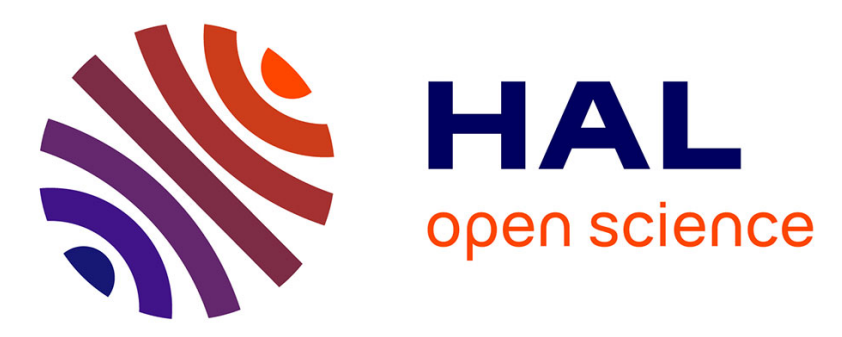

\title{
Influence of automation on mind wandering frequency in sustained attention
}

\author{
Jonas Gouraud, Arnaud Delorme, Bruno Berberian
}

\section{To cite this version:}

Jonas Gouraud, Arnaud Delorme, Bruno Berberian. Influence of automation on mind wandering frequency in sustained attention. Consciousness and Cognition, 2018, 66, pp.54-64. 10.1016/j.concog.2018.09.012 . hal-02314045

\section{HAL Id: hal-02314045 \\ https://hal.science/hal-02314045}

Submitted on 11 Oct 2019

HAL is a multi-disciplinary open access archive for the deposit and dissemination of scientific research documents, whether they are published or not. The documents may come from teaching and research institutions in France or abroad, or from public or private research centers.
L'archive ouverte pluridisciplinaire $\mathbf{H A L}$, est destinée au dépôt et à la diffusion de documents scientifiques de niveau recherche, publiés ou non, émanant des établissements d'enseignement et de recherche français ou étrangers, des laboratoires publics ou privés. 
Running head: INFLUENCE OF AUTOMATION OVER MIND WANDERING

Influence of Automation over Mind Wandering Frequency in Sustained Attention

Jonas Gouraud $^{1}$, Arnaud Delorme ${ }^{2,3}$, Bruno Berberian $^{1}$

1. System and Information Processing Department, ONERA, Salon de Provence, France

2. Center of Research on Brain and Cognition (UMR 5549), CNRS, Toulouse, France

6 California, USA

7

8

9

10 Correspondence concerning this article should be addressed to Jonas Gouraud,

11 ONERA Salon de Provence, 13661, Salon Air, France. Contact: contact@jonasgouraud.com 


\section{Abstract}

14 Recent evidences showing that mind wandering might fill the time saved by automation

15 are particularly worrying when taking into account the negative effect of mind wandering

16 on short-term performance. 17 participants performed an obstacle avoidance task under

17 manual and automated conditions in 2 sessions lasting 45 minutes each. We recorded

18 attentional probes, oculometry and answers to the Task Load Index after each session.

19 Subjects perceived the manual condition as more demanding than the automated one. We

20 highlighted a significant influence of automation on the mind wandering frequency after

21 some time. Multiple phenomena may play a role, such as complacency and decoupling

22 from the task at hand. Pupil diameter decreased during mind wandering versus focus

23 periods, with a stable amplitude. Mind wandering knowledge could be used in a near

24 future to characterize and quantify an operator's state of mind regarding automation

25 related problems.

26 Keywords: mind wandering; automation; vigilance; oculometry; complacency; 


\section{Introduction}

In order to continuously improve system safety, the critical systems industry

31 makes extensive use of automation (Baxter, Rooksby, Wang, \& Khajeh-Hosseini, 2012;

32 Parasuraman, 1987). In cockpits (Wise, Tilden, Abbott, Dyck, \& Guide, 1994), in cars

33 (Naujoks, Purucker, \& Neukum, 2016), and in power plant consoles (Cummings,

34 Sasangohar, Thornburg, Xing, \& D'Agostino, 2010), automation has been introduced to

35 increase performance and respond to new safety requirements. Unfortunately, while

36 implementing higher levels of automation indeed improves the efficiency and capacity of

37 a system, it also creates new challenges for human operators. Particularly, the externally

38 imposed task to maintain sustained attention focused for long periods of time in low

39 probability environments causes progressive vigilance decrement - or invigilance

40 increment (Hancock, 2013) - preventing efficient automation supervising (Amalberti,

41 1999). As targets are hidden - naturally, voluntarily or because of poor display design -,

42 the task to detect and react to these targets is often stressful and increasingly difficult

43 (Mackworth, 1948). These problems result in out-of-the-loop (OOTL) performance

44 problem, referring to a performance decrease whenever attempts are made to regain

45 manual control after a critical system failure.

Such problems have been studied in laboratories (Endsley \& Kiris, 1995; Sarter,

47 Woods, \& Billings, 1997), but are also regularly reported in operational conditions.

48 Mosier and collaborators (1994) examined NASA's Aviation Safety Reporting System

49 (ASRS) database and reported that $77 \%$ of the incidents involved an over-reliance on

50 automation leading to a probable vigilance failure. Similarly, Gerbert and Kemmler

51 (1986) studied German aviators' anonymous responses to questionnaires about 
52 automation-related incidents and pointed out failures of vigilance as the largest

53 contributor to human error. Several studies showed that efficient sustained attention for

54 hours cannot be achieved (Cabon, Coblentz, Mollard, \& Fouillot, 1993; Mackworth,

55 1948; Methot \& Huitema, 1998).

Such a context may favor the occurrence of mind wandering (MW) episodes. MW

57 is a family of experiences relating to the mind's tendency to engage in thoughts unrelated

58 to the here and now (Smallwood \& Schooler, 2006). It is an ubiquitous phenomenon that

59 can be intentional or spontaneous (Golchert et al., 2016; Seli, Risko, \& Smilek, 2016), be

60 guided or unguided (Smallwood, 2013), emerge when performing a task or at rest

61 (Smallwood, Baracaia, Lowe, \& Obonsawin, 2003) while its ignition point can be

62 triggered by the environment or generated internally (McMillan, Kaufman, \& Singer,

63 2013; Smallwood \& Schooler, 2006). In the following paper, we focused on MW when

64 performing a task without discriminating other dimensions. MW is more likely to occur

65 in monotonous environments (Eastwood, Frischen, Fenske, \& Smilek, 2012), or when

66 operators perform familiar (Bastian et al., 2017) or long tasks (Smallwood \& Schooler,

67 2015). Its occurrence favors a decoupling from the ongoing task at perceptual and stimuli

68 processing levels (Kam et al., 2012; Schooler et al., 2011), which can be seen both on

69 behavioral and physiological data. Reading tasks were particularly used to uncover the

70 influence of MW over oculometric markers like blink frequency (Smilek, Carriere, \&

71 Cheyne, 2010b), fixation duration and saccade frequency (Uzzaman \& Joordens, 2011).

72 In simulators, Yanko and Spalek (2014) studied MW influence over driving performance.

73 They observed a longer reaction time to unexpected events, a shorter headway distance

74 and a higher velocity. Their results were corroborated by other studies in driving 
75 environments (Dündar, 2015; He, Becic, Lee, \& McCarley, 2011; Lerner, Baldwin,

76 Higgins, Lee, \& Schooler, 2015).

Given that MW diverts an operator's attention from his primary task, it could play

78 an important role in vigilance failures observed in highly reliable automated

79 environments. Casner and Schooler (2015) studied the impact of automation on MW in

80 an aeronautical context. Their results on 16-minute sessions did not show a significant

81 correlation between automation and the frequency of MW reports. However, the

82 propensity to mind wander appeared to increase when everything seemed under control.

83 Supervising ultra-reliable systems could encourage operators to decrease cognitive

84 resources allocated to the monitoring task. In that context, time saved by automation,

85 which should normally be used for other productive tasks and for monitoring, could

86 instead be filled by task-unrelated thoughts. Operators in such a state would not be

87 prepared to regain manual control over the system in response to rare critical events.

88 Such analysis is already considered in the debate regarding the origin of the vigilance

89 decrement (Fraulini, Hancock, Neigel, Claypoole, \& Szalma, 2017; Pattyn, Neyt,

90 Henderickx, \& Soetens, 2008; Thomson, Besner, \& Smilek, 2016), recent evidences

91 showing that both phenomena share many features (Gouraud, Delorme, \& Berberian, 92 2017).

93 We believe automation might influence MW during longer sessions within

94 ecological environments. We think that this impact may be observable on the MW

95 frequency, as well as on the physiological markers of MW. Our experiment addresses

96 these hypotheses.

97 


\section{Material and methods}

\section{Participants}

101 years old; $M=27.3, S D=6.0)$. The participants enrolled in this study were volunteers

102 from our company (ONERA organization). All participants had normal or corrected-to-

103 normal visual acuity. All participants signed a written declaration of informed consent.

104 The protocol was conducted in accordance with the Declaration of Helsinki.

\section{Task}

Environment. We used the LIPS (Laboratoire d'Interactions Pilote-Système, or

107 Pilot-System Interactions Laboratory) environment developed at the ONERA

108 organization to program our experiment (see Figure 1). An unmanned air vehicle (UAV)

109 depicted as a plane seen from above stayed at the center of a 2D radar 22-inch screen and

110 moved following waypoints arranged in a semi-straight line with clusters of obstacles

111 along the way (every $45 \mathrm{~s}$ on average). Each cluster contained between 1 to 5 obstacles,

112 including one on the trajectory. The participants were instructed to control the

113 movements of the UAV to avoid obstacles. The LIPS environment includes a physics

114 engine to reproduce convincing Rafale aircraft motion behavior. The LIPS was displayed 115 on a screen within the SIMPIT environment shown in Figure 1. 


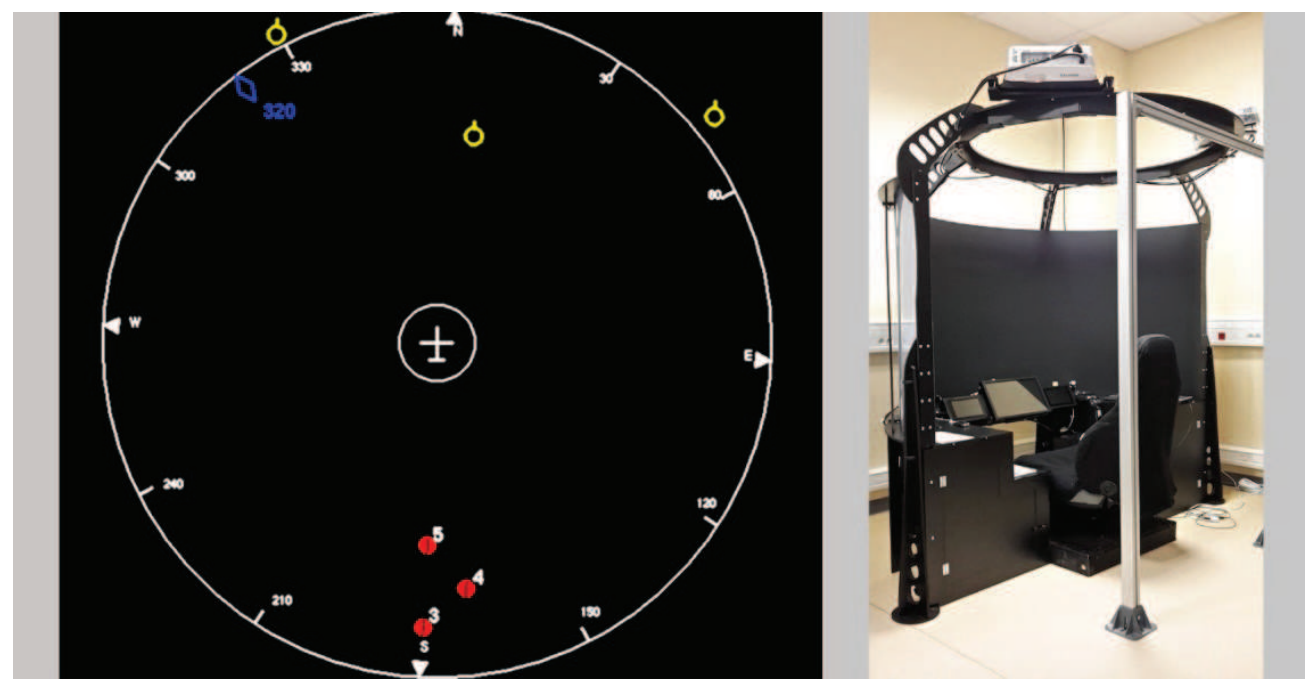

118 Figure 1. Screenshot of the LIPS interface and the environment. One of the screen is used for the task and the 119 other one for questionnaire probes. For the task, the plane in the center is static and the surround (yellow and 120 red numbered symbols) are moving. During, left and right avoidance maneuvers, again the plane is static and the background is rotated.

MW probes. Python 3.6 was used to program mental probes. On average every 2

124 minutes, the probe appeared on a secondary 10-inch screen next to the main screen. For

125 technical reasons, the obstacle avoidance task was not paused when the probe was

126 displayed. Participants were asked to fill it as soon as it appeared, and any successful or

127 failed trial during this interval would not be taken into account. Participants were

128 informed that the probe was not part of the evaluation to lower the impact of instructions

129 over their natural propensity to mind wander. Participants were required to answer the

130 following questions (originally in French, see Figure 2): "When this probe appeared,

131 where was your attention directed?" Answers could be "On the task" (e.g., thinking about

132 the next obstacle, the decision to make, the incoming waypoint), "Something related to

133 the task" (e.g., thinking about performance, interface items, last trial), "Something

134 unrelated to the task" (e.g., thinking about a memory, their last meal, or a body sensation, 
135 hereafter defined as MW) or "External distraction" (e.g., conversation, noise). The

136 preceding examples were given to participants to illustrate each category. We were

137 primarily interested in reports of being "On the task" and MW reports. Reports of

138 thoughts "Related to the task" were integrated to avoid participants to report MW when

139 thinking about their performance (Head \& Helton, 2016). Noises were integrated to avoid

140 participants to report MW if they were focused on any external signal.

Figure 2. Screenshot of the French MW probes. The question is "When this probe appeared, where

Juste avant que ce questionnaire apparaisse, a quoi pensiez-vous?

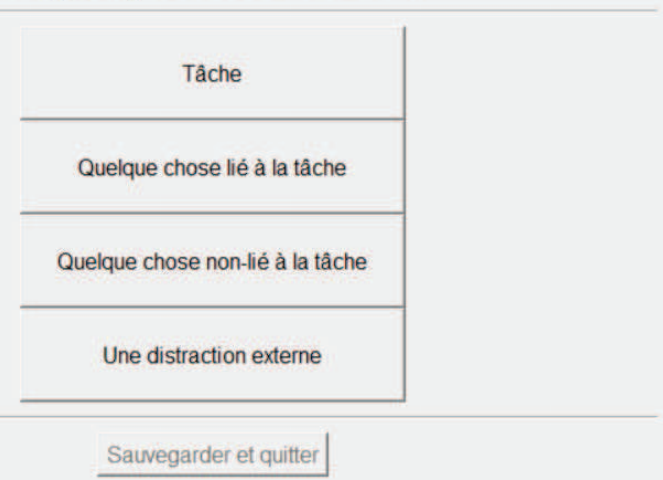

147 Conditions. Two conditions were proposed. The first one was the "manual"

148 condition and required participants to manually avoid obstacles. The system detected

149 obstacles on the trajectory $13 \mathrm{~s}$ before impact. Then, an orange circle appeared around the

150 UAV and the participant could initiate an avoidance maneuver. Participants were able to

151 choose the way in which they wished to avoid the obstacle by clicking on "Evitement

152 Gauche" (left maneuver) or "Evitement Droite" (right maneuver). Once they clicked, the 
153 simulator turned the trajectory of the UAV on the chosen side, following a predefined

154 angle. Each obstacle had a safe circle similar to that of the UAV (see Figure 1). A

155 collision warning - i.e., an orange circle around both the UAV and the obstacle with a

156 message "Collision" - was displayed if the UAV safe circle penetrated inside the obstacle

157 safe circle. A trial with a collision warning triggered was marked as failed. To resume the

158 initial trajectory, they had to click on the "Retour trajectoire" (return to original

159 trajectory) button. If no action was taken within 16 seconds after the first change in

160 trajectory, the aircraft automatically resumed the trajectory and the trial was marked as

161 failed.

162 The second condition was the "automated" condition. Participants were required

163 to monitor the system avoiding obstacles. They had to click on an "Acquittement"

164 (acknowledgement) button to acknowledge automated avoidance decisions as soon as

165 they saw it - twice per trial, once to acknowledge avoidance of the object and once to

166 acknowledge the return to normal trajectory after avoiding the object. A feedback

167 message was displayed to the participants. The acknowledgement ensured that

168 participants would have the same motor input under both the manual and the automated

169 conditions. If participants detected an automation error, i.e. choosing the wrong side for

170 avoidance trajectory, they were instructed to click on the button "Changement d'altitude"

171 (change altitude) so that the UAV would perform an emergency descent. A feedback

172 message was displayed in that case as well. The altitude change ensured that participants

173 were facing a supervision task.

174 Procedure. Participants were explicitly instructed that detection accuracy was

175 more important than speed in button clicks. Each participant performed the two 
176 conditions on two separate days in a counterbalanced way. Each day started with an

177 explanation of the task, followed by a 10-minute training period and a 45-minutes session

178 under the proper condition. Each session contained 60 clusters of obstacles. Each cluster

179 was considered a trial. They were separated by 45 seconds on average. 20 probes were

180 answered under each condition. The distribution of probes was not correlated with events

181 on the obstacle avoidance task in order to avoid performance to influence MW reports

182 (Head \& Helton, 2016). The automated condition included 8 conflicts with a probe within

183 the 10-seconds interval following the conflict. Participants encountered one system error

184 (where they had to click on the "Changement d'altitude" button) during training, and 185 another during the automated condition at the end of the third block. Under the manual 186 condition, participants encountered at the end of the third block a conflict impossible to

187 avoid. Both the automation error and this conflict were not followed by an attentional 188 probe for at least 10 seconds after.

\section{$189 \quad$ Data recording}

190 MW Probes. Comma Separated Value (CSV) text files were used to store all

191 answers. The exact appearance time was saved along with each answer, in order to 192 synchronize probes data with the pupillometric signal.

193 Post-task questionnaire. We used a validated French version of the NASA Task

194 Load Index (TLX) questionnaire to evaluate the required amount of cognitive resources 195 equated as workload - along several dimensions (Cegarra \& Morgado, 2009; Hart \&

196 Staveland, 1988). This questionnaire includes questions pertaining to mental load, time 197 pressure, physical strain, effort, frustration, and perceived performance. Participants were 198 asked to answer each question using a horizontal line, ranging from 0 to 20 . Although a 
199 TLX questionnaire completed at each block would allow precise workload monitoring,

200 we believe that MW would have been artificially lower due to the disruption. Therefore,

201 the TLX was only filled at the end of each session.

202 Oculometry. Oculometric data was recorded using the hardware SmartEye Pro

$203 \quad 3.0$ and the software SmartEye 6.2.4. The system included 2 infrared illuminators and

2043 cameras $(120 \mathrm{~Hz})$ placed above the screen to avoid any direct contact with the

205 participant (see Figure 1). Gaze calibration was performed using a 4-point grid.

206 Performance. We recorded button clicks throughout both conditions. Each button

207 click was saved along with its timestamp within a CSV text format by the LIPS

208 environment.

\section{Data Analysis}

210 MW probes. Participants' clicks and probe answers were saved in CSV text

211 format. We used R-Studio and R 3.4.1 (R Core Team, 2016; RStudio Team, 2015) to

212 analyze the data.

213 Oculometry. The 10 seconds preceding each probe were extracted from

214 oculometric data. This period length is in line with the literature investigating MW and

215 oculometric markers (Bixler \& D’Mello, 2014, 2015; Franklin, Broadway, Mrazek,

216 Smallwood, \& Schooler, 2013; He et al., 2011). Extracts before "On the task" and

217 "Something related to the task" were classified as "Focus" to avoid any influence of poor

218 performance on subsequent attentional reports (Head \& Helton, 2016). Extracts before

219 "Something unrelated to the task" were classified as "MW". Extracts before "External 220 distraction" were discarded as noise. 
We performed filtering on pupillometry using the R package reshape (Wickham,

222 2007), psych (Revelle, 2017), ggplot2 (Wickham, 2009, p. 2) and robfilter (Fried,

223 Schettlinger, \& Borowski, 2014). Filtering was done in two passes, following a method

224 already used in the literature (Grandchamp, Braboszcz, \& Delorme, 2014). Firstly, we

225 filtered the signal. Pupil diameter had to be between 1 and $10 \mathrm{~mm}$ (due to the physical

226 limits of pupil diameter, see (Lemercier, 2014), had to be less than $80 \%$ different from

227 the preceding value (due to pupil dynamic limits) and had to be of a quality (computed by

228 the SmartEye software) over 0.01. Extracts were discarded if their resulting pupil

229 diameter series consisted of less than $70 \%$ compliant values. The proportion of extracts

230 excluded due to low quality $(9.6 \%)$ is in line with that excluded in other investigations

231 (Smallwood et al., 2011). Resulting extracts were completed using basic linear

232 interpolation. A second filtering pass was applied with a median filter (moving window

233 of 50 frames). Finally, the data of each participant were normalized by subtracting the

234 mean and dividing by the root mean square of all good-enough quality extracts for this 235 participant.

236 Fixations, saccades and blinks were computed by the SmartEye Pro software.

237 Blinks were computed using sliding windows of 700ms. Saccades were defined in

238 SmartEye Pro parameters as gaze velocity over $35 \mathrm{deg} / \mathrm{s}$. Saccades were limited to

$239200 \mathrm{~ms}$. Fixations were frames where the gaze velocity remained below $15 \mathrm{deg} / \mathrm{s}$.

$240 \quad$ Performance. Performance was assessed by determining if participants clicked

241 when they were required to do so. Reaction time were computed by comparing

242 participants button click time delay in the manual condition to the moment the system 
243 detected an obstacle, and in the automated condition to the time at which they

244 acknowledged each automation decision.

\section{Results}

\section{Mind Wandering Frequency}

We split the 45-minute sessions into 4 blocks lasting 10-minutes and containing 5

249 reports each. MW propensity was calculated as a percentage of all reports in the block

250 (see Figure 3). Participants reported MW episodes for almost half of the probes $(M=$ $25149 \%, S D=30 \%$ ). This rate is consistent with previous studies on the subject (Kam et al., 252 2011; Smallwood \& Schooler, 2006, 2015). Each participant reported on average 4\% 253 "external distraction" thoughts in each session $(S D=5)$. Such a low rate justified

254 discarding "external distraction" reports as noise without thwarting subsequent analysis.

We used the ezANOVA function (Lawrence, 2016) to perform a two-way

256 repeated measure ANOVA. We entered time (block) and level of automation (condition)

257 as independent variables. We used the MW frequency as a dependent variable. Mauchly's

258 test indicated that the assumption of sphericity had been verified for the main effect of

259 block, $W=0.64, p=.251$, and block $\times$ condition, $W=0.90, p=.906$. There were

260 significant main effects of time over the MW frequency, $F(3,48)=8.88, p<.001$, as

261 well as of the level of automation over the MW frequency, $F(1,16)=12.67, p=.003$.

262 There was also a significant interaction effect between the time and the level of

263 automation, $F(3,48)=5.22, p=.003$. Without specific a priori predictions on the

264 evolution of MW frequency through time, we conducted Tukey's post-hoc tests on the

265 model including Block variable for each condition separately. We used the glht (Hothorn 
266 et al., 2017) and mes (AC Del Re, 2014) functions. For the manual condition, all

267 differences were non-significant $(\mathrm{p}>.366)$. For the automated condition, the third and

268 fourth blocks had significantly higher MW frequency compared to the first block, $p=$

$269.001, d=0.54$ and $p=.003, d=0.32$, respectively. Similarly, the blocks 3 and 4 had

270 significantly higher MW frequency compared to the block $2, p=.007, d=0.12$ and $p=$

$271.016, d=0.12$, respectively.

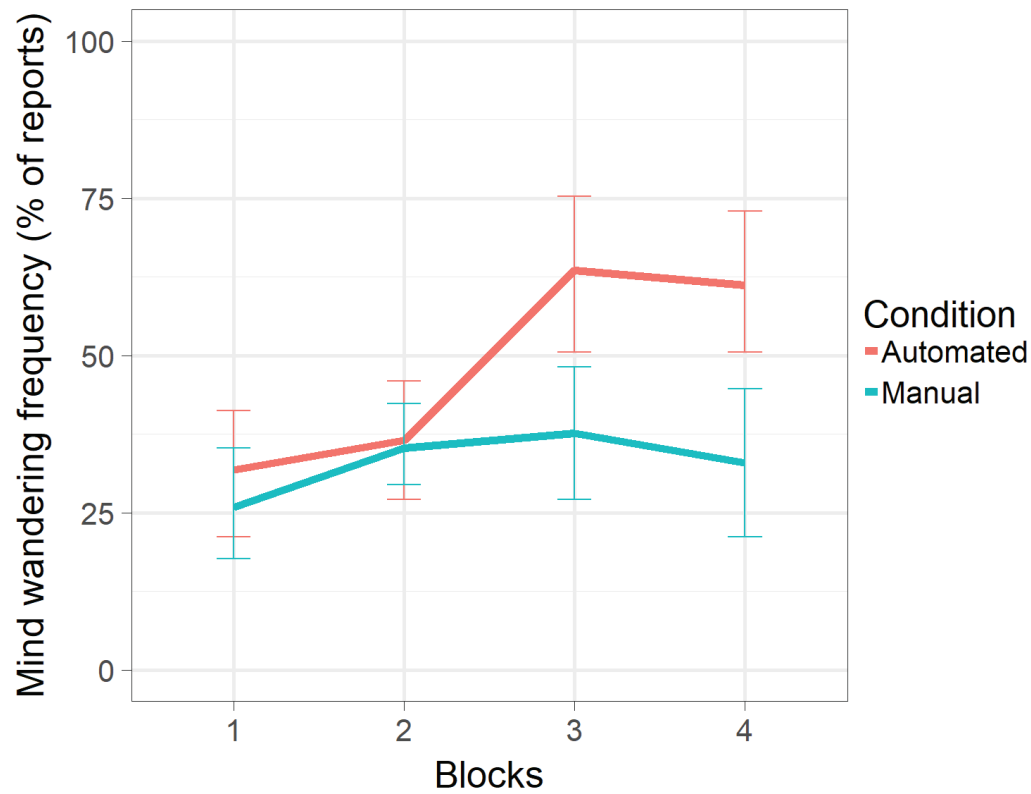

Figure 3: MW frequency evolution according to the condition. Error bars show the $95 \%$ confidence

279 score for each TLX of each subject (see Figure 4) varied substantially (ranging from 2 to $28014.17, M=5.81, S D=2.44)$. Shapiro-Wilk's test indicated that the assumption of normality had been violated for the TLX values, $W=.921, p=.012$. Therefore, we used 
282 Wilcox's robust version of the $t$-test proposed in the WRS2 package (Mair, Schoenbrodt, $283 \&$ Wilcox, 2017). On average, participants perceived that the automated $(M=4.93, S D=$ $284.50)$ condition required more cognitive resources than the manual $(M=6.68, S D=.61)$ 285 condition, $t(10)=-3.35, p=.007, d=0.78$. TLX scores show that our automated 286 condition succeeded in lowering workload.

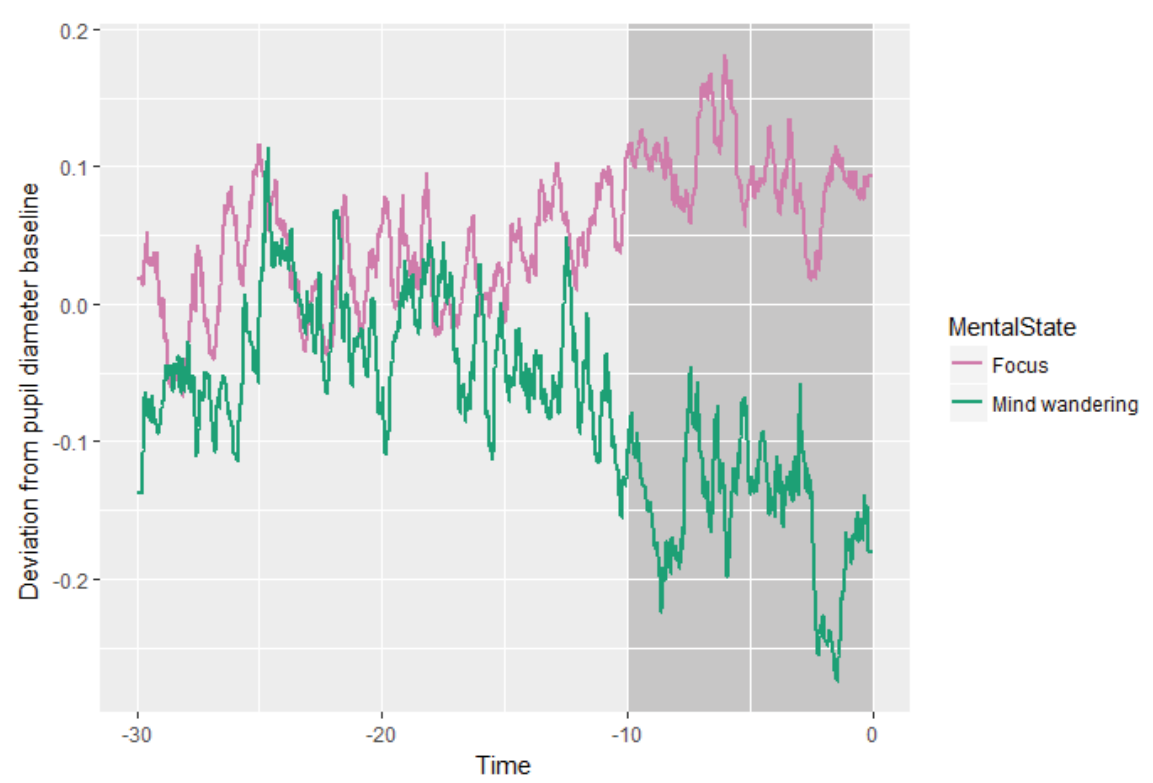

Figure 4: Normalized pupil diameter. Evolution during the 30-second interval preceding probes display - the grey part of the signal is used for computation

\section{Oculometry}

Influence of MW over oculometric measures. Oculometric measures were first analyzed using the 10 seconds preceding each probe. We used the lmer function (Bates,

296 Maechler, Bolker, \& Walker, 2015, p. 4) to perform a linear mixed-effect analysis despite 297 missing values - "external distraction" reports and bad quality extracts excluded. As 
298 random effects, we had intercepts for subjects. Visual inspection of residual plots did not

299 reveal any obvious deviations from normality or homoscedasticity. P-values were

300 obtained by likelihood ratio tests using ANOVA on the full model against the models

301 with no fixed effect, with only block, with block and condition, and with block and

302 condition and their interaction. The results are shown in Table 1. On average, participants

303 showed a significantly smaller pupil during MW episodes (see Figure 4). There was no

304 main effect of MW on other markers.

Table 1: Comparison of oculometric measures during MW and focus episodes

\begin{tabular}{|l|c|c|c|c|c|c|}
\hline \multirow{2}{*}{ Parameter } & \multicolumn{2}{|c|}{ MW values } & \multicolumn{2}{c|}{ Focus values } & \multicolumn{2}{c|}{ Mental State model } \\
\hline & $M$ & $S D$ & $M$ & $S D$ & $\chi^{2}(1)$ & p-value \\
\hline Pupil size (mm) & 4.90 & 0.97 & 5.05 & 0.97 & $\mathbf{7 2 5 9}$ & $<.001$ \\
\hline Saccade frequency (sacc/s) & 3.92 & 2.36 & 3.89 & 2.39 & 0.07 & .795 \\
\hline Mean fixation duration (s) & $2.87 * 10^{-1}$ & $6.65^{*} 10^{-1}$ & $3.22^{*} 10^{-1}$ & $6.52 * 10^{-1}$ & 0.08 & .774 \\
\hline Blink frequency (blink/s) & $6.90^{-1} 10^{-2}$ & $1.10^{*} 10^{-1}$ & $5.43^{-1} 10^{-2}$ & $9.81 * 10^{-2}$ & 2.09 & .148 \\
\hline
\end{tabular}

Influence of time and automation on oculometric differences. We looked for

309 any influence of time or automation over the pupillometric differences previously

310 observed between MW and focus periods. We used the lmer function to perform the

311 linear mixed-effect analysis, as in the previous paragraph. As fixed effects, we entered

312 time (block), level of automation (condition) and their interaction. As random effects, we

313 had intercepts for subjects, as well as by-subject random slopes for the effect of block and

314 condition. Visual inspection of residual plots did not reveal any obvious deviations from

315 normality and homoscedasticity. Results are gathered in Table 2. Pupillometric difference

316 remained stable through time and condition. 
Table 2: Influence of time and level of automation over the difference

\begin{tabular}{|l|c|c|c|c|c|c|}
\hline Parameter & \multicolumn{2}{|c|}{ Time model } & \multicolumn{2}{c|}{ Time +Condition model } & \multicolumn{2}{c|}{ Time*Condition model } \\
\hline & $\chi^{2}(3)$ & $\mathrm{p}$-value & $\chi^{2}(1)$ & $\mathrm{p}$-value & $\chi^{2}(3)$ & $\mathrm{p}$-value \\
\hline Pupil size & 1.83 & .609 & 0.40 & .528 & 0.30 & .959 \\
\hline
\end{tabular}

We studied the impact of automated compared to manual environments on MW

322 and its behavioral and oculometric markers. The automated condition revealed

323 significantly lower TLX scores compared to the manual condition, showing a protocol in

324 line with usual goals regarding automation introduction (Wiener, 1988). Performance

325 remained very high throughout both conditions whereas MW increased in the automated

326 condition, ruling out the possibility that our attentional reports might be significantly

327 influenced by poor performance (Head \& Helton, 2016). This demonstrates that our

328 results were as close as possible to ecological settings. Building on this, three main

329 results have been shown: (1) MW increases after some time has elapsed in an automated

330 environment, (2) there is a difference in pupil diameter between MW and focus episodes

331 but not for other oculometric markers and (3) pupillometric difference between

332 attentional states remains stable through time and condition. We discuss these results 333 below.

334 The first result is the significant increase of the MW frequency under the 335 automated condition between blocks two and three. No significant time-related evolution 336 of MW was observed under the manual condition. Since both conditions lasted the same 337 amount of time, had similar number of actions and pursued the same goal - avoid 338 incoming obstacles -, time-related phenomena (drowsiness, habituation, tiredness) cannot 
339 explain entirely the fact that MW increased only under the automated condition. The

340 absence of MW increase in the manual condition is interesting considering the well-

341 established vigilance decrement observed in sustained attention (Cabon et al., 1993;

342 Davies \& Parasuraman, 1982; Jeroski, Miller, Langhals, \& Tripp, 2014; Mackworth,

343 1948). It may point to a fundamental difference between MW and vigilance decrement

344 when considering the influence of automation. However mediating factors have still to be

345 investigated, such as anxiety and motivation, which have demonstrated essential link with

346 both phenomena separately (Killingsworth \& Gilbert, 2010; Szalma et al., 2004; Szalma

$347 \&$ Matthews, 2015). Nevertheless, the level of automation alone cannot explain the

348 observed data. Even though MW frequency highlighted significant differences between

349 conditions, the trend did not evolve linearly with time-on-task and showed no difference

350 between conditions for the first two blocks. Moreover, this evolution happened despite

351 TLX scores remaining low for both conditions, which rules out the possibility that MW

352 may be explained by workload evolution. Together, these findings argue for an effect

353 linked to time spent supervising automation.

354 There are two explanations, which may be complementary, for this interaction

355 between time and level of automation over MW frequency. First, complacency might be

356 generated by the high reliability of the system and lower monitoring performance.

357 Complacency is an issue of monitoring automation generated by an uncritical reliance on 358 the system (Parasuraman, Molloy, \& Singh, 1993). Complacency has been linked to

359 higher reaction time (Bahner, Hüper, \& Manzey, 2008; Manzey, Bahner, \& Hüper, 360 2006), loss of situation awareness (Endsley \& Kiris, 1995) and failures of detection 361 (Parasuraman et al., 1993). In our experiment, participants encountered no error during 
362 the first three blocks. Given that the system never did any miss or error, participants may

363 have thought that it would remain perfectly reliable. In this context, their perception of

364 the required workload might evolve: since the automated system does not seem to require

365 their attention to function properly, participants would redirect their cognitive resources

366 towards more personal matters and mind-wander more. The higher perceived workload

367 under the manual condition supports our analysis. Moreover, this could explain why

368 participants, novice in supervising the system, exhibited an increase of MW frequency

369 only after some time, while pilots in Casner and Schooler (2015), who were pilots with

370 thousands of hours dealing with autopilot, mind wandered immediately without temporal

371 evolution. These evidences suggest a mediating influence of system familiarity in MW

372 frequency temporal evolution. This position would introduce a third possibility within the

373 overload/underload theory debate (Pattyn et al., 2008; Warm, Parasuraman, \& Matthews,

374 2008). Although the task complexity does not change, the operator's perception could

375 evolve based on their trust in the system and their feelings toward the overall situation.

376 As pointed by Seli and colleagues (Seli, Carriere, \& Smilek, 2015; Seli et al., 2016), there

377 is strong evidence that people can exert some control over their MW. This follows Casner

378 and Schooler's (2015) results, who demonstrated that cognitive resources freed by

379 automation in peaceful situations are not allocated to task planning, but rather to MW.

380 Our analysis is in line with studies that observed MW increase in a low probability signal 381 environment (Berthié et al., 2015; Casner \& Schooler, 2015; Galera et al., 2012), with the 382 time elapsed performing the task (McVay \& Kane, 2009; Smallwood, Baracaia, Lowe, \&

383 Obonsawin, 2003; Smallwood, Riby, Heim, \& Davies, 2006) and the view of

384 complacency as a multiple-task strategy (Bahner et al., 2008; Moray \& Inagaki, 2000). 
385 Operators save cognitive resources allocated to the low-event automated task in order to 386 perform better on another task - MW -, which is considered more interesting or useful, 387 independently of experiment instructions.

388 The second possible explanation is a decoupling of operators' attention from the 389 task at hand. When dealing with automation, operators give up their direct control over 390 the system for a monitoring role in the supervisory control loop (Moray, 1986; Sheridan, 391 1992). They may experience a loss of agency - i.e., the ability to feel in control (Wegner, 392 2002). Multiple studies pointed to a limit to the automation level beyond which users felt 393 less in control (Berberian, Sarrazin, Le Blaye, \& Haggard, 2012; Coyle, Moore, 394 Kristensson, Fletcher, \& Blackwell, 2012), leading to a form of disengagement from the 395 task at hand (Haggard, 2017). Interestingly, Szalma (2014) described a similar 396 disengagement when applying the Self-Determination Theory (Ryan \& Deci, 2000) to 397 human-system interactions. The inability of a system to support autonomous behavior 398 may lower motivation and create an externalization of task goals - i.e. a process by which 399 operators rejects the value of a goal. In our experiment, since participants do not validate 400 but rather only acknowledge the system's actions, they could firstly experience a loss of 401 agency, their motivation would decrease, leading to a faint sense of responsibility. This 402 process chain could lead participants to reallocate cognitive resources from the task to 403 MW, unconsciously trying to optimize time and mental resources from their perspective. 404 Further studies are needed to distinguish the respective impacts of agency drop and 405 complacency on MW emergence.

406 Our second result concerns oculometric measures. We highlighted a lower pupil 407 diameter during MW, as did several studies on MW (Faber, Bixler, \& D’Mello, 2017; 
408 Grandchamp et al., 2014; Mittner et al., 2014). Our probes included action required for 8 409 out of 20 probes in each condition, ruling out the possibility that performance may have

410 significantly influenced subsequent attentional reports (Head \& Helton, 2016). Moreover,

411 literature on vigilance already linked a lower pupil baseline to periods of lower sensibility

412 to external stimuli (K. McIntire, P. McIntire, Mckinley, \& Goodyear, 2014; Nishiyama,

413 Tanida, Kusumi, \& Hirata, 2007). Taken together, these results are in line with the view

414 of MW as a phenomenon inducing a decoupling from the environment. However, other

415 research linked large pupils with slow and inaccurate responses (Gilzenrat, Nieuwenhuis,

416 Jepma, \& Cohen, 2010; Smallwood et al., 2011), or more directly to MW during a word-

417 by-word reading task (Franklin et al., 2013). A recent study by Konishi et al. (2017) was

418 aimed at explaining these results to all appearances contradictory. During 0-back and 1-

419 back tasks, they observed a smaller pupil preceding MW reports. They also linked a

420 higher pupil baseline and slower or inaccurate responses, highlighting a different state of

421 under-processing of external stimuli and ruling out a potential increase in pupil diameter

422 during MW episodes. These results corroborate our study and stress the need to

423 investigate these attentional states. Contrary to pupillometry, other oculometric measures

424 did not exhibit significant sensitivity to MW. However, our experiment is the first to our

425 knowledge to investigate MW influence over blink, saccade frequency and fixation

426 duration in operational settings. Indeed, previous research used most exclusively reading

427 tasks (Bixler \& D’Mello, 2014, 2015; Reichle, Reineberg, \& Schooler, 2010; D. Smilek

428 et al., 2010; Uzzaman \& Joordens, 2011), with the notable exception of meditation

429 (Grandchamp et al., 2014). Our result could point to important task mediators of MW

430 influence over oculometric markers, such as event rate or cognitive demands. 
Finally, the last result is the stability of pupillometric markers with respect to

432 automation and time. Cheyne and colleagues (2009) recently proposed the integration of

433 intensity of environment decoupling as a characteristic of MW episodes. They used a

434 Sustained Attention to Response Task (SART, a form of GO/NOGO task; see

435 (Robertson, Manly, Andrade, Baddeley, \& Yiend, 1997) to match errors and reaction

436 time evolution with each level of their model. If this model were true, there is little doubt

437 that physiological markers would show some sensibility to intensity of MW. However, no

438 influence over oculometric markers was observed. Several explanations can be proposed.

439 First, our protocol, which differ from previous protocols, may not be able to uncover such

440 a tendency. Second, intensity may not regulate MW impact over pupillometry. Third,

441 there may not be any intensity in MW episodes, each inducing the same environment

442 decoupling. Indeed, the study Cheyne and colleagues (2009) falls under the concerns

443 expressed by Head and Helton (2016), see next paragraph). Further neural studies are

444 necessary to answer this question.

445 One could argue about the absence of analysis of performances, in order to clarify

446 the relation between MW and stimuli processing. However, our study aimed to explore a

447 different question: the impact of automation on MW occurrence. Addressing both

448 questions would have required modifications to our protocol - add more conflicts,

449 increase the duration, synchronize probes with conflicts -, with the possibility to 450 introduce biases and produce an environment far from an ecological one. In such 451 condition, OOTL phenomenon occurrence would be difficult to induce. Nevertheless, the question of how MW influences performance remains to be

453 answered. The extended literature on the subject (Esterman, Noonan, Rosenberg, \& 
454 DeGutis, 2013; Smallwood et al., 2003; Smilek, Carriere, \& Cheyne, 2010a; Thomson, 455 Seli, Besner, \& Smilek, 2014) was recently criticized by Head and Helton (2016). They 456 put forward the possibility that poor performance observed before MW may influence 457 subsequent attentional reports, and not the other way around. The result of their reading 458 study did not show any significant link between MW and awareness of stimuli. Certainly, 459 studies using high rates of discrete events without high cognition - like the Sustained 460 Attention to Response Task (SART) - may be particularly biased by this logical flaw, as 461 performance monitoring and self-corrections are easy to perform. On the other hand, 462 continuous metrics - as in tracking tasks (Kam et al., 2012; Yanko \& Spalek, 2014) 463 cannot be similarly biased, as poor performance evaluation is harder and would lead to a 464 direct correction visible in the signal. Similarly, studies measuring stimuli awareness or 465 recognition - like reading - may avoid this flaw, as performance is evaluated either at the 466 end of the session (Franklin et al., 2013), or not at all (Uzzaman \& Joordens, 2011). Be 467 that as it may, further research is needed to identify parameters mediating the perceptual 468 decoupling induced by MW.

469 In the near future, the massive use of automation in everyday systems will 470 reinforce the OOTL phenomenon. Our results show that automation increases MW 471 frequency after some time. The MW literature in ecological tasks already highlighted 472 how the phenomenon increases the risks in critical environments. Such results stress the 473 necessity to study in more detail the relation between MW and the OOTL performance 474 problem. Possible improvements include the study of reliability and complacency by 475 manipulating the number of conflicts and automation errors. Another possibility is to 476 highlight the impact of the operator's engagement in the task. Finally, perceived 
477 workload is not to be overlooked. The use of electroencephalograms would allow

478 continuous measurement to precisely assess its impact over MW frequency. However,

479 such a protocol requires the influence of perceived workload and MW over neural

480 measures to be discriminated. Eventually, the expected outcome is to design automated

481 systems able to adapt themselves to operators' MW episodes. We hope that such a system

482 may enhance safety in critical automated environments.

Acknowledgements

We thank the Direction Générale de l'Armement (DGA) for their financial

486 support to the first author. This work was supported by the Agence Nationale de la

487 Recherche (grant ANR-15-CE26-0010-01).

\section{References}

490 1. AC Del Re. (2014). compute.es: Compute Effect Sizes (Version 0.2-4). Retrieved 491 from https://CRAN.R-project.org/package=compute.es

492 2. Amalberti, R. (1999). Automation in aviation: A human factors perspective. In D.

493 J. Garland, J. Wise, \& D. Hopkin (Eds.), Aviation Human Factors (pp. 173-192).

$494 \quad$ Hillsdale, New Jersey: Lawrence Erlbaum Associates. Retrieved from http://www.irit.fr/SIGCHI/old/docs/debat/Automation.in.Avia.LEA98\%27.doc

3. Bahner, J. E., Hüper, A.-D., \& Manzey, D. (2008). Misuse of automated decision aids: Complacency, automation bias and the impact of training experience. International Journal of Human-Computer Studies, 66(9), 688-699. https://doi.org/10.1016/j.ijhcs.2008.06.001 
4. Bastian, M., Lerique, S., Adam, V., Franklin, M. S., Schooler, J. W., \& Sackur, J. (2017). Language facilitates introspection: Verbal mind-wandering has privileged access to consciousness. Consciousness and Cognition, 49, 86-97. https://doi.org/10.1016/j.concog.2017.01.002

5. Bates, D., Maechler, M., Bolker, B., \& Walker, S. (2015). Fitting Linear MixedEffects Models Using lme4. Journal of Statistical Software, 67(1), 1-48. https://doi.org/doi:10.18637/jss.v067.i01

6. Baxter, G., Rooksby, J., Wang, Y., \& Khajeh-Hosseini, A. (2012). The ironies of 508 automation ... still going strong at 30? In Proceedings of ECCE 2012 Conference. Edinburgh, North Britain.

7. Berberian, B., Sarrazin, J.-C., Le Blaye, P., \& Haggard, P. (2012). Automation Technology and Sense of Control: A Window on Human Agency. PLoS ONE, 7(3), e34075. https://doi.org/10.1371/journal.pone.0034075

8. Berthié, G., Lemercier, C., Paubel, P.-V., Cour, M., Fort, A., Galera, C., ... Maury, B. (2015). The restless mind while driving: drivers' thoughts behind the wheel. Accident Analysis \& Prevention, 76, 159-165. https://doi.org/10.1016/j.aap.2015.01.005

9. Bixler, R., \& D’Mello, S. (2014). Toward Fully Automated Person-Independent Detection of Mind Wandering. In User Modeling, Adaptation, and Personalization (pp. 37-48). Springer. Retrieved from http://link.springer.com/chapter/10.1007/978-3-319-08786-3_4 detection of mind wandering during computerized reading. In Proceedings of the 
23rd User Modeling and User-Adapted Interactions conference (pp. 31-43).

Dublin, Ireland. https://doi.org/10.1007/s11257-015-9167-1

11. Cabon, P., Coblentz, A., Mollard, R., \& Fouillot, J. P. (1993). Human vigilance in railway and long-haul flight operation. Ergonomics, 36(9), 1019-1033. https://doi.org/10.1080/00140139308967974

12. Casner, S. M., \& Schooler, J. W. (2015). Vigilance impossible: Diligence, distraction, and daydreaming all lead to failures in a practical monitoring task. Consciousness and Cognition, 35, 33-41. https://doi.org/10.1016/j.concog.2015.04.019

13. Cegarra, J., \& Morgado, N. (2009). Étude des propriétés de la version francophone du NASATLX. In B. Cahour, F. Anceaux, \& A. Giboin (Eds.), Acte du 5ème colloque de psychologie ergonomique (EPIQUE’2009) (pp. 233-239). Nice, France.

14. Cheyne, A. J., Solman, G. J. F., Carriere, J. S. A., \& Smilek, D. (2009). Anatomy of an error: A bidirectional state model of task engagement/disengagement and attention-related errors. Cognition, 111(1), 98-113. https://doi.org/10.1016/j.cognition.2008.12.009

15. Coyle, D., Moore, J., Kristensson, P. O., Fletcher, P., \& Blackwell, A. (2012). I did that! Measuring users' experience of agency in their own actions. In Proceedings of the SIGCHI Conference on Human Factors in Computing Systems (pp. 2025-2034). Austin, TX: ACM. https://doi.org/10.1145/1518701.1518766 (2010). Human-system interface complexity and opacity part i: literature review. 

https://www.researchgate.net/profile/Farzan_Sasangohar/publication/263315585 Humansystem_interface_complexity_and_opacity/links/0deec53accc4413fb2000000.pdf

17. Davies, D. R., \& Parasuraman, R. (1982). The psychology of vigilance. London, England: Academic Press.

18. Dündar, C. (2015). The effects of mind wandering on simulated driving performance. Retrieved from http://etd.lib.metu.edu.tr/upload/12618921/index.pdf

19. Eastwood, J. D., Frischen, A., Fenske, M. J., \& Smilek, D. (2012). The Unengaged Mind: Defining Boredom in Terms of Attention. Perspectives on Psychological Science, 7(5), 482-495. https://doi.org/10.1177/1745691612456044

20. Endsley, M. R., \& Kiris, E. O. (1995). The out-of-the-loop performance problem and level of control in automation. Human Factors: The Journal of the Human Factors and Ergonomics Society, 37(2), 381-394.

21. Esterman, M., Noonan, S. K., Rosenberg, M., \& DeGutis, J. (2013). In the Zone or Zoning Out? Tracking Behavioral and Neural Fluctuations During Sustained Attention. Cerebral Cortex, 23(11), 2712-2723. https://doi.org/10.1093/cercor/bhs261 of mind wandering during computerized reading. Behavior Research Methods. https://doi.org/10.3758/s13428-017-0857-y 
23. Franklin, M. S., Broadway, J. M., Mrazek, M. D., Smallwood, J., \& Schooler, J. W. (2013). Window to the wandering mind: Pupillometry of spontaneous thought while reading. The Quarterly Journal of Experimental Psychology, 66(12), 22892294. https://doi.org/10.1080/17470218.2013.858170

24. Fraulini, N. W., Hancock, G. M., Neigel, A. R., Claypoole, V. L., \& Szalma, J. L. (2017). A critical examination of the research and theoretical underpinnings discussed in Thomson, Besner, and Smilek (2016). Psychological Review, 124(4), 525-531. https://doi.org/10.1037/rev0000066

25. Fried, R., Schettlinger, K., \& Borowski, M. (2014). robfilter: Robust Time Series Filters (Version 4.1). Retrieved from https://CRAN.Rproject.org/package $=$ robfilter

26. Galera, C., Orriols, L., M'Bailara, K., Laborey, M., Contrand, B., RibereauGayon, R., ... Lagarde, E. (2012). Mind wandering and driving: responsibility case-control study. British Medical Journal, 345(dec13 8), e8105-e8105. https://doi.org/10.1136/bmj.e8105

27. Gerbert, K., \& Kemmler, R. (1986). The causes of causes: determinants and background variables of human factor incidents and accidents. Ergonomics, 29(11), 1439-1453. https://doi.org/10.1080/00140138608967257

28. Gilzenrat, M. S., Nieuwenhuis, S., Jepma, M., \& Cohen, J. D. (2010). Pupil diameter tracks changes in control state predicted by the adaptive gain theory of locus coeruleus function. Cognitive, Affective, \& Behavioral Neuroscience, 10(2), 252-269. https://doi.org/10.3758/CABN.10.2.252 
29. Golchert, J., Smallwood, J., Jefferies, E., Seli, P., Huntenburg, J. M., Liem, F., ... Margulies, D. S. (2016). Individual variation in intentionality in the mindwandering state is reflected in the integration of the default-mode, fronto-parietal, and limbic networks. NeuroImage, 146, 226-235. https://doi.org/10.1016/j.neuroimage.2016.11.025

30. Gouraud, J., Delorme, A., \& Berberian, B. (2017). Autopilot, Mind Wandering, and the Out of the Loop Performance Problem. Frontiers in Neuroscience, 11. https://doi.org/10.3389/fnins.2017.00541

31. Grandchamp, R., Braboszcz, C., \& Delorme, A. (2014). Oculometric variations 600 during mind wandering. Frontiers in Psychology, 5. https://doi.org/10.3389/fpsyg.2014.00031

32. Haggard, P. (2017). Sense of agency in the human brain. Nature Reviews Neuroscience, 18(4), 196-207. https://doi.org/10.1038/nrn.2017.14

33. Hancock, P. A. (2013). In search of vigilance: The problem of iatrogenically created psychological phenomena. American Psychologist, 68(2), 97-109. https://doi.org/10.1037/a0030214 Index): Results of empirical and theoretical research. Advances in Psychology, 52, 139-203.

612 36. He, J., Becic, E., Lee, Y.-C., \& McCarley, J. S. (2011). Mind Wandering Behind 613 the Wheel: Performance and Oculomotor Correlates. Human Factors: The 
Journal of the Human Factors and Ergonomics Society, 53(1), 17-21. https://doi.org/10.1177/0018720810391530

37. Hothorn, T., Bretz, F., Westfall, P., Herberger M., R., Schuetzenmeister, A., \& Schreibe, S. (2017). multComp: Simultaneous Inference in General Parametric Models (Version 1.4-8). Retrieved from https://CRAN.Rproject.org/package $=$ multcomp

38. Jeroski, J., Miller, M. E., Langhals, B., \& Tripp, L. (2014). Impact of Vigilance Decrement upon Physiology Measures. In IIE Annual Conference. Proceedings (p. 1184). Institute of Industrial Engineers-Publisher. Retrieved from http://www.xcdsystem.com/iie2014/abstract/finalpapers/I471.pdf (2012). Mind wandering and motor control: off-task thinking disrupts the online adjustment of behavior. Frontiers in Human Neuroscience, 6. https://doi.org/10.3389/fnhum.2012.00329 40. Kam, J. W. Y., Dao, E., Farley, J., Fitzpatrick, K., Smallwood, J., Schooler, J. W., \& Handy, T. C. (2011). Slow fluctuations in attentional control of sensory cortex. Journal of Cognitive Neuroscience, 23(2), 460-470.

41. Killingsworth, M. A., \& Gilbert, D. T. (2010). A Wandering Mind Is an Unhappy Mind. Science, 330(6006), 932-932. https://doi.org/10.1126/science.1192439 of vigilance performance with pupillometry. In Proceedings of the Symposium on Eye Tracking Research and Applications (pp. 167-174). Safety Harbor, FL, USA: ACM. 
43. Konishi, M., Brown, K., Battaglini, L., \& Smallwood, J. (2017). When attention wanders: Pupillometric signatures of fluctuations in external attention. Cognition, 168, 16-26. https://doi.org/10.1016/j.cognition.2017.06.006

44. Lawrence, M. A. (2016). ez: Easy Analysis and Visualization of Factorial Experiments (Version 4.4-0). Retrieved from https://CRAN.Rproject.org/package $=\mathrm{ez}$

45. Lemercier, A. (2014). Développement de la pupillométrie pour la mesure objective des émotions dans le contexte de la consommation alimentaire (Psychologie). Université Paris 8.

46. Lerner, N., Baldwin, C., Higgins, J. S., Lee, J., \& Schooler, J. (2015). Mind Wandering While Driving: What Does it Mean and What do we do about it? Proceedings of the Human Factors and Ergonomics Society Annual Meeting, 59(1), 1686-1690. https://doi.org/10.1177/1541931215591364

47. Mackworth, N. H. (1948). The breakdown of vigilance during prolonged visual search. Quaterly Journal of Experimental Psychology, 1, 6-14. https://doi.org/10.1080/17470214808416738 and testing.

49. Manzey, D., Bahner, J. E., \& Hüper, A.-D. (2006). Misuse of automated aids in process control: Complacency, automation bias and possible training interventions. In Proceedings of the Human Factors and Ergonomics Society Annual Meeting (Vol. 50, pp. 220-224). Los Angeles, CA: Sage Publications. 
Retrieved from

http://journals.sagepub.com/doi/abs/10.1177/154193120605000303

50. McMillan, R. L., Kaufman, S. B., \& Singer, J. L. (2013). Ode to positive constructive daydreaming. Frontiers in Psychology, 4. https://doi.org/10.3389/fpsyg.2013.00626

51. McVay, J. C., \& Kane, M. J. (2009). Conducting the train of thought: working memory capacity, goal neglect, and mind wandering in an executive-control task. Journal of Experimental Psychology: Learning, Memory, and Cognition, 35(1), 196.

52. Methot, L. L., \& Huitema, B. E. (1998). Effects of signal probability on individual differences in vigilance. Human Factors: The Journal of the Human Factors and Ergonomics Society, 40(1), 102-110.

53. Mittner, M., Boekel, W., Tucker, A. M., Turner, B. M., Heathcote, A., \& Forstmann, B. U. (2014). When the Brain Takes a Break: A Model-Based Analysis of Mind Wandering. Journal of Neuroscience, 34(49), 16286-16295. https://doi.org/10.1523/JNEUROSCI.2062-14.2014

54. Moray, N. (1986). Monitoring behavior and supervisory control. In K. Boff (Ed.), Handbook of perception and human performance (Vol. 2, pp. 1-51). New York, NY: Wiley. in Ergonomics Science, 1(4), 354-365. https://doi.org/10.1080/14639220052399159 
56. Mosier, K. L., Skitka, L. J., \& Korte, K. J. (1994). Cognitive and social psychological issues in flight crew/automation interaction. In M. Mouloua \& R. Parasuraman (Eds.), Human performance in automated systems: current research and trends (pp. 191-197). Cambridge: University Press.

57. Naujoks, F., Purucker, C., \& Neukum, A. (2016). Secondary task engagement and vehicle automation - Comparing the effects of different automation levels in an on-road experiment. Transportation Research Part F: Traffic Psychology and Behaviour, 38, 67-82. https://doi.org/10.1016/j.trf.2016.01.011

58. Nishiyama, J., Tanida, K., Kusumi, M., \& Hirata, Y. (2007). The pupil as a possible premonitor of drowsiness. In 29th Annual International Conference of the IEEE (pp. 1586-1589). Lyon, France: IEEE. https://doi.org/10.1016/j.neuron.2015.09.012

59. Parasuraman, R. (1987). Human-computer monitoring. Human Factors: The Journal of the Human Factors and Ergonomics Society, 29(6), 695-706.

60. Parasuraman, R., Molloy, R., \& Singh, I. L. (1993). Performance Consequences of Automation-Induced "Complacency." The International Journal of Aviation Psychology, 3(1), 1-23.

61. Pattyn, N., Neyt, X., Henderickx, D., \& Soetens, E. (2008). Psychophysiological investigation of vigilance decrement: Boredom or cognitive fatigue? Physiology \& Behavior, 93(1-2), 369-378. https://doi.org/10.1016/j.physbeh.2007.09.016

62. R Core Team. (2016). R: A language and environment for statistical computing. Vienna, Austria: R Foundation for Statistical Computing. Retrieved from https://www.R-project.org/ 
63. Reichle, E. D., Reineberg, A. E., \& Schooler, J. W. (2010). Eye Movements During Mindless Reading. Psychological Science, 21(9), 1300-1310. https://doi.org/10.1177/0956797610378686

64. Revelle, W. (2017). psych: Procedures for Personality and Psychological Research (Version 1.7.5). Evanston, Illinois, USA: Northwestern University. Retrieved from https://CRAN.R-project.org/package=psych

65. Robertson, I. H., Manly, T., Andrade, J., Baddeley, B. T., \& Yiend, J. (1997). “Oops!”: Performance correlates of everyday attentional failures in traumatic brain injured and normal subjects. Neuropsychologia, 35(6), 747-758.

66. RStudio Team. (2015). RStudio: Integrated Development for R (Version 1.0.143). Boston, MA, USA: RStudio Inc. Retrieved from http://www.rstudio.com/ of intrinsic motivation, social development, and well-being. American Psychologist, 55(1), 68.

68. Sarter, N. B., Woods, D. D., \& Billings, C. E. (1997). Automation surprises. Handbook of Human Factors and Ergonomics, 2, 1926-1943. Sayette, M. A. (2011). Meta-awareness, perceptual decoupling and the wandering equal: dissociating deliberate from spontaneous mind wandering. Psychological Research, 79(5), 750-758. https://doi.org/10.1007/s00426-014-0617-x 
71. Seli, P., Risko, E. F., \& Smilek, D. (2016). On the necessity of distinguishing between unintentional and intentional mind wandering. Psychological Science, 27(5), 685-691. https://doi.org/10.1177/0956797616634068

72. Sheridan, T. B. (1992). Telerobotics, automation, and human supervisory control. Cambridge: MIT Press.

73. Smallwood, J. (2013). Distinguishing how from why the mind wanders: A process-occurrence framework for self-generated mental activity. Psychological Bulletin, 139(3), 519-535. https://doi.org/10.1037/a0030010

74. Smallwood, J., Baracaia, S. F., Lowe, M., \& Obonsawin, M. (2003). Task unrelated thought whilst encoding information. Consciousness and Cognition, 12(3), 452-484. https://doi.org/10.1016/S1053-8100(03)00018-7

75. Smallwood, J., Brown, K. S., Tipper, C., Giesbrecht, B., Franklin, M. S., Mrazek, M. D., ... Schooler, J. W. (2011). Pupillometric Evidence for the Decoupling of Attention from Perceptual Input during Offline Thought. PLoS ONE, 6(3), e18298. https://doi.org/10.1371/journal.pone.0018298

76. Smallwood, J., Riby, L., Heim, D., \& Davies, J. B. (2006). Encoding during the attentional lapse: Accuracy of encoding during the semantic sustained attention to response task. Consciousness and Cognition, 15(1), 218-231. https://doi.org/10.1016/j.concog.2005.03.003 Bulletin, 132(6), 946-958. https://doi.org/10.1037/0033-2909.132.6.946 Empirically Navigating the Stream of Consciousness. Annual Review of 
Psychology, 66(1), 487-518. https://doi.org/10.1146/annurev-psych-010814015331

79. Smilek, D., Carriere, J. S. A., \& Cheyne, J. A. (2010a). Failures of sustained attention in life, lab, and brain: Ecological validity of the SART. Neuropsychologia, 48(9), 2564-2570. https://doi.org/10.1016/j.neuropsychologia.2010.05.002

80. Smilek, D., Carriere, J. S. A., \& Cheyne, J. A. (2010b). Out of Mind, Out of Sight: Eye Blinking as Indicator and Embodiment of Mind Wandering. Psychological Science, 21(6), 786-789.

81. Szalma, J. L. (2014). On the Application of Motivation Theory to Human Factors/Ergonomics: Motivational Design Principles for Human-Technology Interaction. Human Factors, 56(8), pp. 1453-1471. https://doi.org/10.1177/0018720814553471

82. Szalma, J. L., \& Matthews, G. (2015). Motivation and Emotion in Sustained Attention.

83. Szalma, J. L., Warm, J. S., Matthews, G., Dember, W. N., Weiler, E. M., Meier, A., \& Eggemeier, F. T. (2004). Effects of sensory modality and task duration on performance, workload, and stress in sustained attention. Human Factors: The Journal of the Human Factors and Ergonomics Society, 46(2), 219-233. evidence for sensitivity loss in modern vigilance tasks. Psychological Review, 123(1), 70-83. https://doi.org/10.1037/rev0000021 
85. Thomson, D. R., Seli, P., Besner, D., \& Smilek, D. (2014). On the link between mind wandering and task performance over time. Consciousness and Cognition, 27, 14-26. https://doi.org/10.1016/j.concog.2014.04.001

86. Uzzaman, S., \& Joordens, S. (2011). The eyes know what you are thinking: Eye movements as an objective measure of mind wandering. Consciousness and Cognition, 20(4), 1882-1886. https://doi.org/10.1016/j.concog.2011.09.010

87. Warm, J. S., Parasuraman, R., \& Matthews, G. (2008). Vigilance Requires Hard Mental Work and Is Stressful. Human Factors: The Journal of the Human Factors and Ergonomics Society, 50(3), 433-441. https://doi.org/10.1518/001872008X312152

88. Wegner, D. M. (2002). The Illusion of Conscious Will (MA: MIT Press). Cambridge.

89. Wickham, H. (2007). Reshaping data with the reshape package. Journal of Statistical Software, 21(12).

90. Wickham, H. (2009). ggplot2: Elegant Graphics for Data Analysis. SpringerVerlag New York.

91. Wiener, E. L. (1988). Cockpit automation. National Aeronautics and Space Administration. Retrieved from http://ntrs.nasa.gov/search.jsp?R=19890047073 92. Wise, J. A., Tilden, D. S., Abbott, D., Dyck, J., \& Guide, P. (1994). Managing automation in the cockpit. In Proceedings of the 24th International Conference of the International Federation of Airworthiness. Lisbon, Portugal. Retrieved from http://www.faa.gov/training_testing/training/media/cfit/volume2/pdf/pages/page5 - 07.pdf 
93. Yanko, M. R., \& Spalek, T. M. (2014). Driving With the Wandering Mind: The Effect That Mind-Wandering Has on Driving Performance. Human Factors: The Journal of the Human Factors and Ergonomics Society, 56(2), 260-269.

799 https://doi.org/10.1177/0018720813495280

800 


\section{Figure 1}

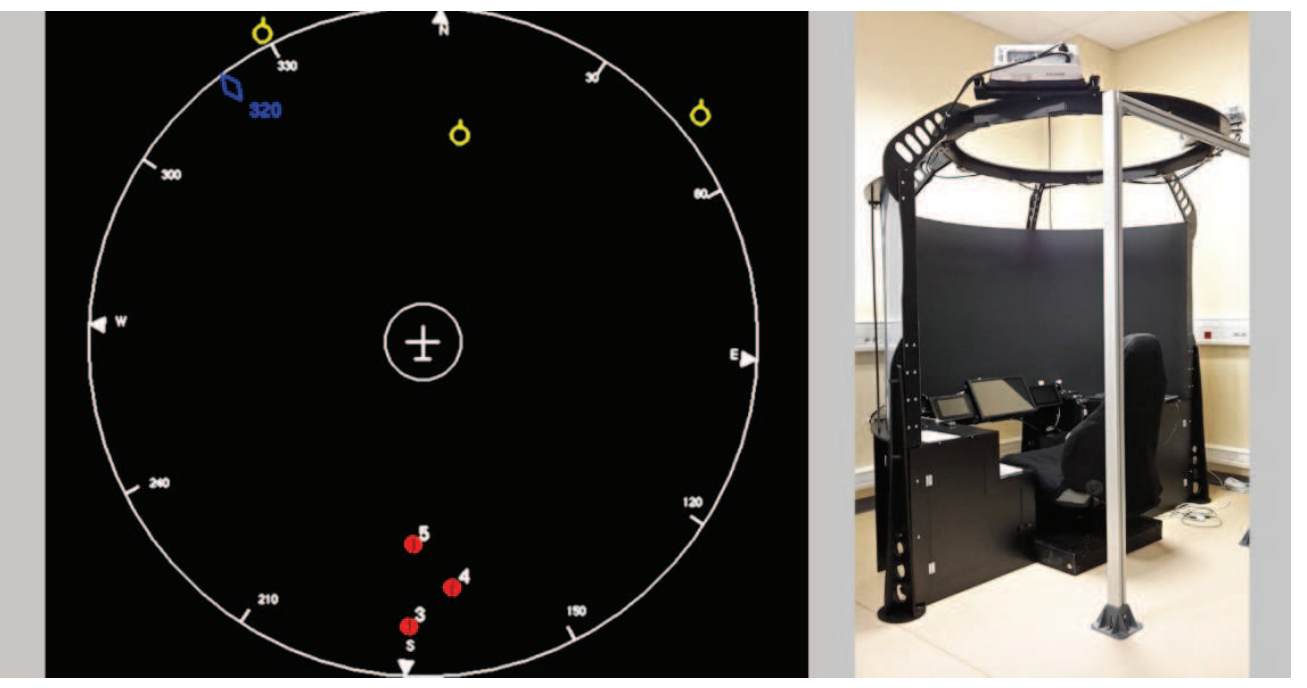

Figure 1. Screenshot of the LIPS interface and the environment. One of the screen is used for the task and the other one for questionnaire probes. For the task, the plane in the center is static and the surround (yellow and red numbered symbols) are moving. During, left and right avoidance maneuvers, again the plane is static and the background is rotated. 


\section{Figure 2}

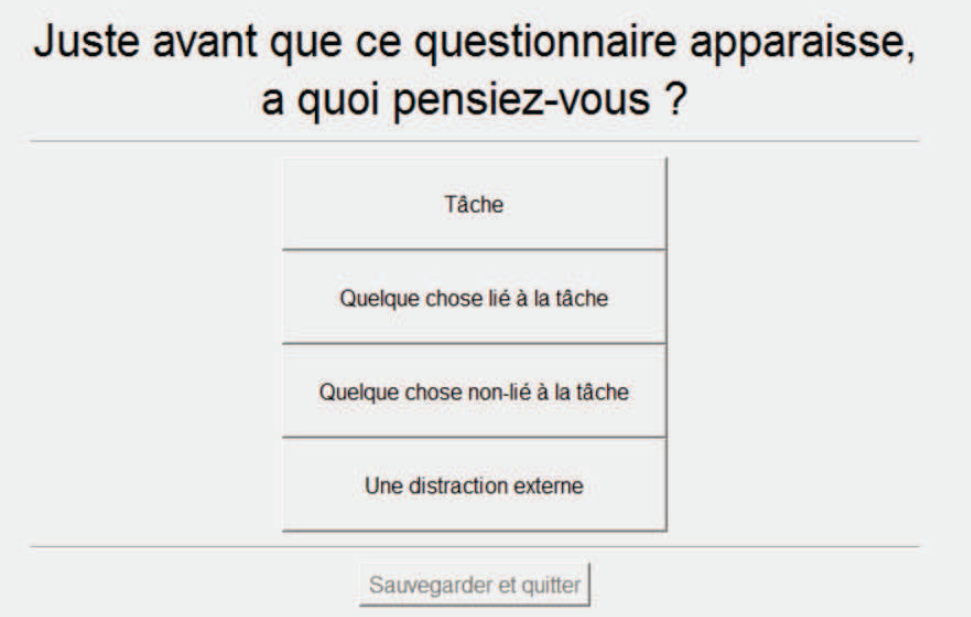

Figure 2. Screenshot of the French MW probes. The question is "When this probe appeared, where was your attention directed?" Answers could be "On the task", "Something related to the task", "Something unrelated to the task" or "External distraction" 


\section{Figure 3}

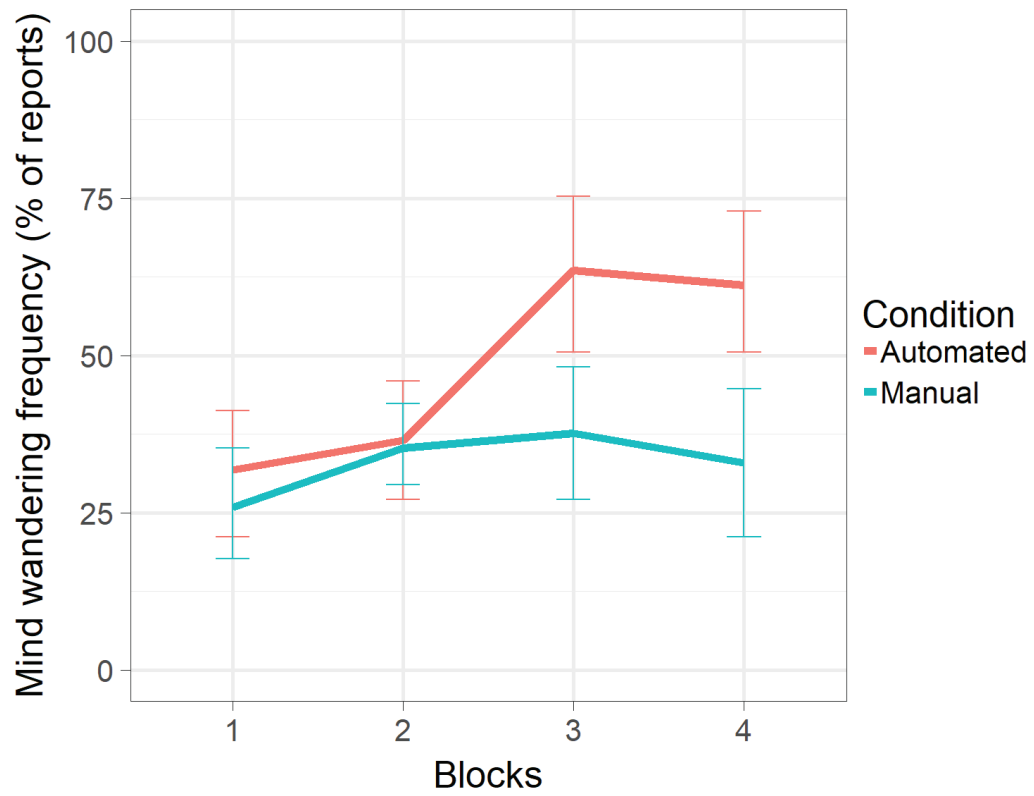

Figure 3: MW frequency evolution according to the condition. Error bars show the $95 \%$ confidence intervals based on bootstrap 


\section{Figure 4}

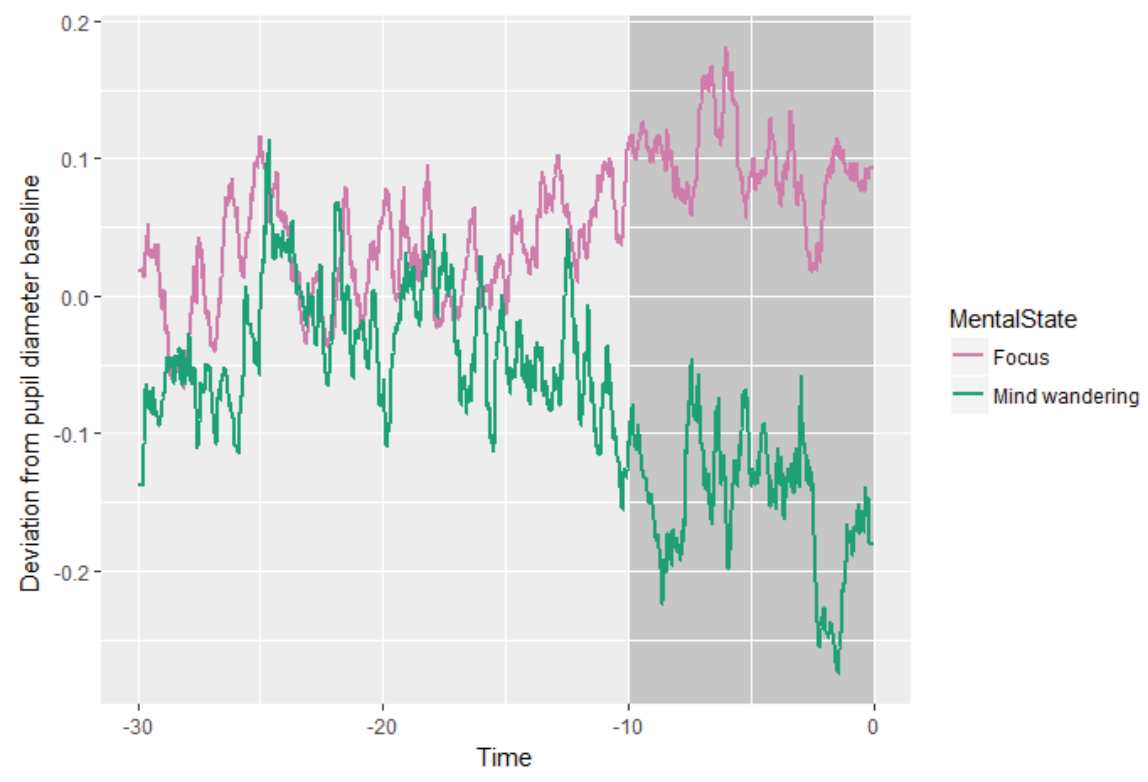

Figure 4: Normalized pupil diameter. Evolution during the 30-second interval preceding probes display the grey part of the signal is used for computation 


\section{Table 1}

Table 1: Comparison of oculometric measures during MW and focus episodes

\begin{tabular}{|l|c|c|c|c|c|c|}
\hline Parameter & \multicolumn{2}{|c|}{ MW values } & \multicolumn{2}{c|}{ Focus values } & \multicolumn{2}{c|}{ Mental State model } \\
\hline & $M$ & $S D$ & $M$ & $S D$ & $\chi^{2}(1)$ & p-value \\
\hline Pupil size (mm) & 4.90 & 0.97 & 5.05 & 0.97 & $\mathbf{7 2 5 9}$ & $<.001$ \\
\hline Saccade frequency (sacc/s) & 3.92 & 2.36 & 3.89 & 2.39 & 0.07 & .795 \\
\hline Mean fixation duration (s) & $2.87 * 10^{-1}$ & $6.65^{*} 10^{-1}$ & $3.22^{*} 10^{-1}$ & $6.52^{*} 10^{-1}$ & 0.08 & .774 \\
\hline Blink frequency (blink/s) & $6.90^{-1} 10^{-2}$ & $1.10^{*} 10^{-1}$ & $5.43^{-2} 10^{-2}$ & $9.81 * 10^{-2}$ & 2.09 & .148 \\
\hline
\end{tabular}




\section{Table 2}

Table 2: Influence of time and level of automation over the difference

\begin{tabular}{|l|c|c|c|c|c|c|}
\hline Parameter & \multicolumn{2}{|c|}{ Time model } & \multicolumn{2}{c|}{ Time +Condition model } & \multicolumn{2}{c|}{ Time*Condition model } \\
\hline & $\chi^{2}(3)$ & $\mathrm{p}$-value & $\chi^{2}(1)$ & $\mathrm{p}$-value & $\chi^{2}(3)$ & $\mathrm{p}$-value \\
\hline Pupil size & 1.83 & .609 & 0.40 & .528 & 0.30 & .959 \\
\hline
\end{tabular}

